\title{
A Modular Actuator Architecture For Robotic Applications
}

Industry Programs

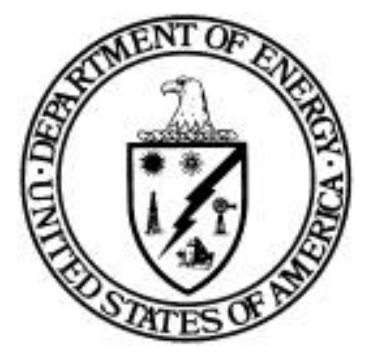

Prepared for

U.S. Department of Energy Office of Environmental Management Office of Science and Technology

July 2001 


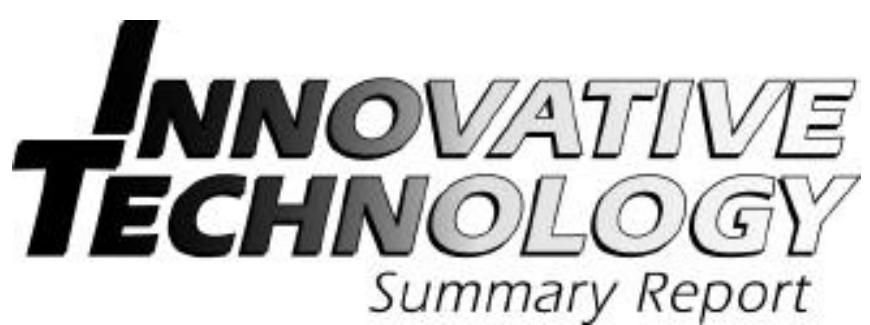

\section{A Modular Actuator Architecture For Robotic Applications}

OST/TMS ID XXX

Industry Programs

Demonstrated at ARM Automation, Inc. Austin, Texas 


\section{WNOVALIUE
TECHNOLOGL \\ Summary Report}

\section{Purpose of this document}

Innovative Technology Summary Reports are designed to provide potential users with the information they need to quickly determine whether a technology would apply to a particular environmental management problem. They are also designed for readers who may recommend that a technology be considered by prospective users.

Each report describes a technology, system, or process that has been developed and tested with funding from DOE's Office of Science and Technology (OST). A report presents the full range of problems that a technology, system, or process will address and its advantages to the DOE cleanup in terms of system performance, cost, and cleanup effectiveness. Most reports include comparisons to baseline technologies as well as other competing technologies.

Information about commercial availability and technology readiness for implementation is also included. Innovative Technology Summary Reports are intended to provide summary information. References for more detailed information are provided in an appendix.

Efforts have been made to provide key data describing the performance, cost, and regulatory acceptance of the technology. If this information was not available at the time of publication, the omission is noted.

All published Innovative Technology Summary Reports are available on the OST Web site at http://ost.em.doe.gov under "Publications." 


\section{TABLE OF CONTENTS}

1. SUMMARY

2. TECHNOLOGY DESCRIPTION

3. PERFORMANCE

4. TECHNOLOGY APPLICABILITY AND ALTERNATIVES

5. COST

6. REGULATORY AND POLICY ISSUES

7. LESSONS LEARNED page 1

page 5

page 10

page 13

page 14

page 17

page 18

page 21

page 23 


\section{SECTION 1 \\ SUMMARY}

\section{Technology Summary}

\section{Problem}

The United States Department of Energy (DOE) Complexes perform numerous hazardous material handling operations within the confines of a glovebox. The DOE is continuing to seek more efficient and safer means of handling these materials inside gloveboxes rather than the conventional, labor-intensive method through lead lined gloves. Glovebox applications exist within all EM Focus Areas (FA) as well as other programs within the DOE; D\&D [1]; Mixed Waste (MW) [2], Materials Disposition (MD) [3], [4] and Defense Programs (DP) [5]. There are many needs within the DOE Complex requiring glovebox automation but the most immediate needs are those summarized in [6], pgs. 40-42, which call out specific sites (LANL, ANL, HAN, SNL, SRS and RFETS) that require an immediate infusion of glovebox automation in order to meet the DOE's commitment outlined in the Ten Year Plan and reiterated in [7]. The use of glovebox automation technology will also be critical to the DOE in its efforts to comply with its mandated ALARA principles in handling the hazardous materials associated with the cleanup process.

Operations associated with materials processing in a glovebox are similar to many industrial tasks, but the unique glovebox environment and Plutonium material properties create a unique set of challenges for conventional automation machinery. Such properties include: Low to moderate levels of ionizing radiation, high abrasiveness, corrosiveness, pyrophoric tendencies, rapid dispersal and permeation of environment, diffuses quickly, and possible incompatible material interaction. The glovebox presents the following challenges: existing gloveboxes may not be readily altered or even modified at all, complex mechanical operations for maintenance and repair are difficult or impossible through gloves, failed equipment may not be removed easily or at all. If a broken piece of equipment cannot be bagged-out through a glove port (approximately $216 \mathrm{~mm}\left(8^{1 / 2} 2^{\prime \prime}\right)$ diameter) it must remain in place. Broken equipment obstructs further operations. If it renders the entire glovebox unusable, a significant volume of waste is generated and an expensive system must be disposed of and replaced. A moderate sized glovebox alone costs between $\$ 250,000$ and $\$ 500,000$ and an equipment malfunction, which penetrates the glovebox and exposes the room to Plutonium or other toxic materials, is catastrophic. In addition to the human exposure issues, cleanup can easily run into the millions of dollars.

\section{Solution}

A solution to the issues described above is ARM Automation Inc.'s (ARM) modular robotic manipulator technology developed for DOE EM operations, which addresses many of the issues discussed in the previous section. This manipulator system has the capability of custom configurations, which accommodate common glovebox tasks such as materials repackaging. The modular nature and quick connects of this system simplify installations into "hot" boxes and any potential modifications or repair therein.

In the field of automation and robotics, a very common element is one used to generate motion for precise positioning of loads. One example of such an automation component would be an individual joint within an industrial robotic manipulator. This component consists of a tightly integrated package containing an electric motor, gear train, output support bearings, position sensors, brake, servo-amplifier and communications controller. Within the context of this paper, this key building block is referred to as an actuator module.

With regard to the needs of the EM, [8] and [9] have shown that while each focus area has unique requirements for robotic automation at a system or manipulator level, their requirements at the actuator level are very similar. Thereby, a modular approach to automation which utilizes a small set of versatile actuator modules can be used to construct a broad range of robotic systems and automation cells suited to EM applications. By providing a pre-engineered, pre-integrated motion system to different robotics users within the DOE, new automation systems can be more quickly created without extensive expertise in motion control or the expense of building custom equipment. 

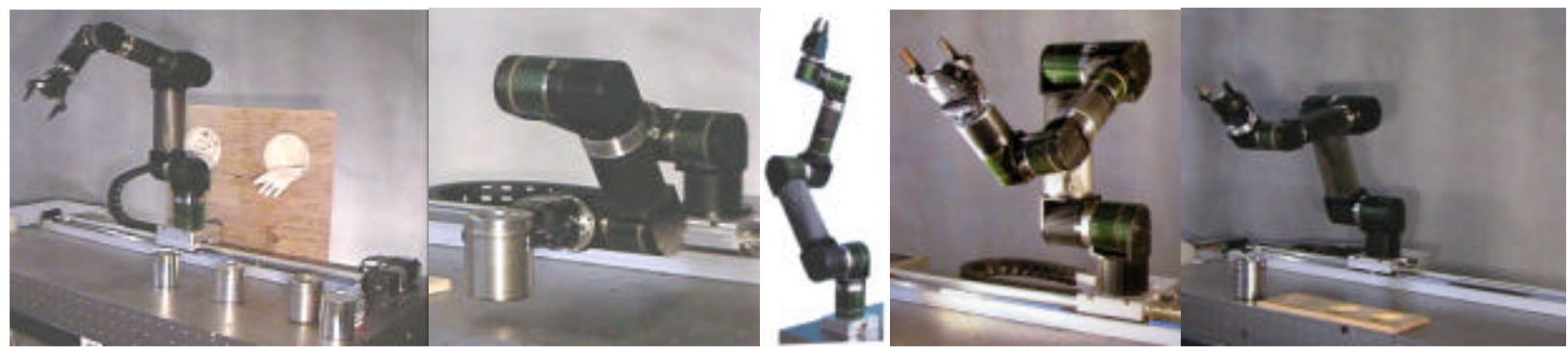

Figure 1: Various manipulator configurations built from two module sizes.

This savings in time, expense and effort to deploy new systems allows focus and resources to be directed at solving EM specific problems using automation in lieu of building new automation tools. Furthermore, the modular architecture, combined with quick-connect interfaces, allows robotic systems to be easily moved or repaired in the field. This is something previously impossible or unthinkable for many automation applications. In all, this modular approach to robotics can reduce overall time and cost to accomplish EM objectives where automation is involved.

\section{How It Works}

ARM's line of modular components is built upon a core technology called the DISC'M. DISC'M stands for Distributed Intelligent Servo Control. Each DISC ${ }^{\mathrm{TM}}$ device is a miniature control and digital communications node, which may be linked with other DISC ${ }^{\mathrm{TM}}$ devices to create a distributed control network of motion devices and sensors. The versatility, ease of use and small size of these controllers allows them to be tightly integrated with and distributed throughout the mechanical structure, thereby reducing system size, cost, design, wiring, maintenance and overall complexity. The reduction in wiring realized by the distributed approach is mandatory to make the mechanical modularity feasible. Each actuator module, motor and interface in ARM's architecture utilizes this technology. Through the commonality and versatility of this controller, an entire family of automation devices can be created which share a common distributed control architecture, communications protocol, programming scheme and simplified electrical interface.

Each DISC ${ }^{\mathrm{TM}}$ device is comprised of two halves. The first is the Control and Communications Interface $(\mathrm{CCl})$ board. This control and communications board is then directly mated with an application specific power or analog circuit board suited to a given task. Most commonly, the DISC ${ }^{\mathrm{TM}}$ controller is mated with a Power and Sensor Interface (PSI) board of similar proportions to create a high-end servo-amplifier for controlling individual electric motors or actuators. At present, all DISC ${ }^{\mathrm{TM}}$ devices utilize an industry standard communications protocol called SERCOS. This open protocol provides deterministic, high-speed communications and is supported by many vendors of motion control components. This token ring architecture allows for a single communications link between all devices under system control.

Together with customizable structural links, end-of arm tooling and open architecture system controllers, this small set of components comprise a versatile system from which a very broad range of automation systems can be constructed. Figure 1 shows some of the configurations developed from just two module sizes.

\section{Potential Markets}

There are many needs within the DOE Complex requiring glovebox automation but the most immediate needs that require an immediate infusion of glovebox automation in order to meet the DOE's commitment outlined in [7] are those summarized in [6], pgs. 40-42; [10], [11], and [12] including the following DOE complexes:

- Savannah River Site (SRS), Aiken, South Carolina;

- Los Alamos National Laboratory (LANL), Los Alamos, New Mexico;

- Rocky Flats Environmental Technology Site (RFETS), Golden, Colorado;

- Sandia National Laboratory (SNL), Albuquerque, New Mexico;

- Hanford Site (HAN), Richmond, Washington; and

- Argonne National Laboratory (ANL), Argonne, Illinois.

\section{Advantages Over Baseline Technology}



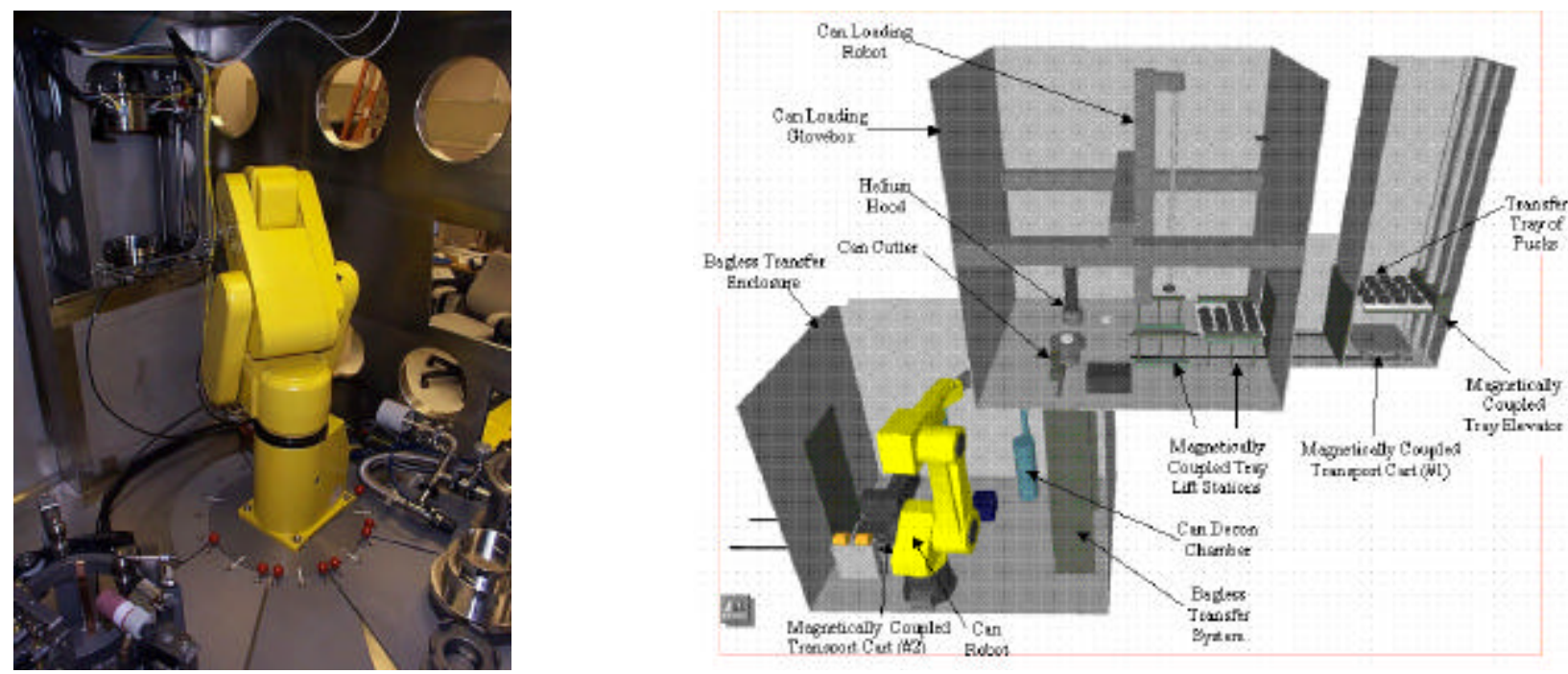

Figure 2. DOE uses of the LR Mate: a) ARIES at LANL and b) PIPs at SRS.

The baseline technology used for comparison purposes is a Fanuc LR-Mate 100i used by LANL in ARIES (Figure 2a) and proposed for use by SRS in PIP's stage-3 material handling system (Figure 2b). ARM's modular robotic technology has significant advantages over the baseline:

- Increased net payload to weight ratio from approx. 1:11 to 1:3 with an increase in maximum wrist payload from $3 \mathrm{~kg}$ to $12 \mathrm{~kg}$ for the same reach;

- Reduced the umbilical cord from 100 wires to 12 wires;

- Demonstrated at least 5 custom configurations using the modular technology;

- The modules are a repairable unit that can easily be bagged in or out of a glovebox whereas the LRMate has to be considered a disposable unit upon failure;

- The modular robot can be calibrated, broken down, passed through a glovebox port and reconfigured inside an existing glovebox to within a demonstrated accuracy of $0.5 \mathrm{~mm}$.

\section{Demonstration Summary}

The system demonstration consisted of two parts: 1) demonstrating the usefulness of the quick connects for passing the modules through the glove port and then assembling the manipulator and 2) demonstrating the insertion of a convenience can into a stainless steel primary can.

\section{Assembly Of Manipulator Using Quick Connects}

Figure 3 depicts the assembly sequence of a modular manipulator using quick connects. A joint, link and half of a quick connect are assembled external to the glovebox and then passed into the glovebox through a glove port. The simplicity of the quick connects allows a manipulator to be assembled/disassembled in a matter of minutes. Since the quick connect is a very accurate interface, a manipulator can be assembled external to the glovebox and then fully qualified before it is disassembled and passed into a confined environment.
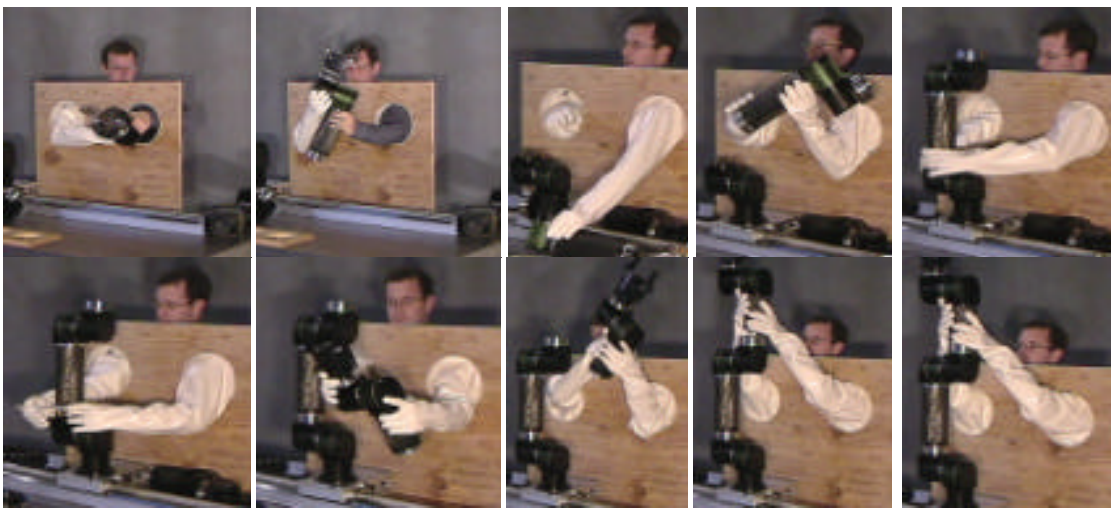

Figure 3. Assembly sequence of a 4 DOF manipulator using gloves. 

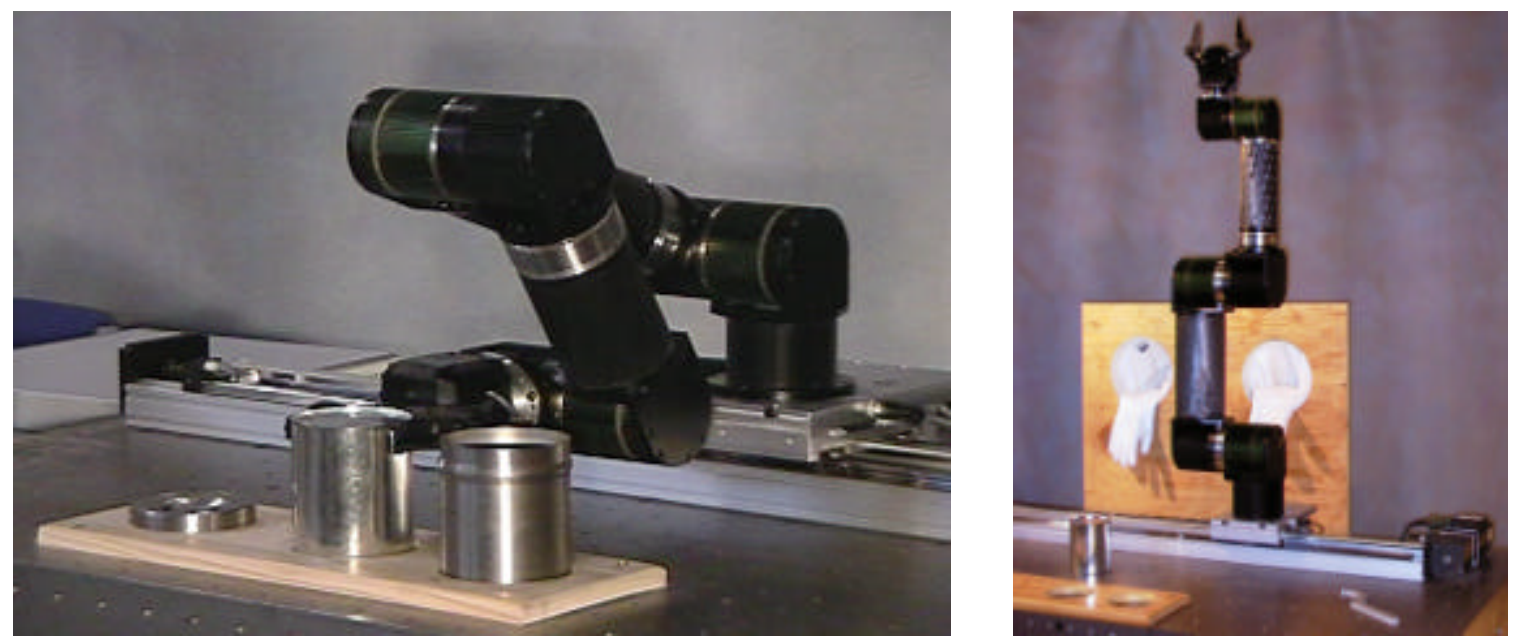

Figure 4. Configuration of manipulators used in demonstration.

\section{Assembly Of A Convenience Can Inside A Primary Can}

There are several procedures associated with the processing of pure Plutonium into a MOX fuel. A simple demonstration of the capabilities of the modular manipulator developed under this project is the assembly of a convenience can inside a stainless steel primary can. A convenience can is a hermetically sealed can that contains Plutonium MOX fuel that has been converted from weapon's grade Plutonium.

Two demonstrations were performed, one with an empty convenience can using a 4 DOF system with the arm consisting of ARM20s (Figure 4a) and one with a full can weighing $4.8 \mathrm{~kg}$ using a 4 DOF system comprised of ARM32s for the lower two joints and an ARM20 for the distal joint (Figure 4b). A jig was manufactured for positioning the convenience container, primary container and lid. This test not only demonstrated the repeatability of the manipulator but also the agility of the kinematics of the given configuration.

\section{Contacts}

\section{Technical}

Joseph W. Geisinger, Principal Investigator, ARM Automation, Inc. (512) 894-3534,

joewg@armautomation.com

Stephen Grupinski, Program Manager, ARM Automation, Inc. (512) 894-3534, stevegru@armautomation.com

Dennis C. Haley, D\&D Robotics Coordinator for the Robotics Technology Development Program, Oak Ridge National Laboratory (423) 576-4388, haleydc@ornl.gov

\section{Management}

Robert Bedick, Industry Programs Lead, DOE-NETL, Morgantown, WV, (304) 285-4505, robert.bedick@netl.doe.gov

Vijendra Kothari, NETL Project Manager, DOE-NETL, Morgantown, WV, (304) 285-4579, vijendra.kothari@netl.doe.gov

\section{Licensing Information}

No additional licensing or permitting activities were required to support this demonstration.

\section{Other}

All published Innovative Technology Summary Reports are available on the OST Web site at http://ost.em.doe.gov under "Publications." The Technology Management System (TMS), also available through the OST Web site, provides information about OST programs, technologies, and problems. The OST/TMS ID for [insert technology name] is [insert number]. 


\section{SECTION 2 \\ TECHNOLOGY DESCRIPTION}

\section{Overall Technology Definition}

Each actuator module in this family of modular "building blocks" is based upon a core technology called the DISC $^{\text {TM. E}}$. Each DISCTM device is a miniature control and communications node which can be linked with other DISCTM devices to create a distributed control network of motion devices and sensors. DISC ${ }^{\text {TM }}$ devices communicate over an industrial communications protocol called SERCOS, which is specifically designed for high-speed communications between motion control devices. The distributed control combined with this digital communications protocol provides noise immunity, real-time communications and, most importantly, reduces the large number of control wires associated with traditional motion control systems to a single twisted pair or fiber optic ring. By providing a uniform interface to each element of an automation cell at the hardware, software and protocol levels, complex automation systems can be designed, built and maintained with less time and expertise required by conventional approaches.

In order to construct a series of robotic manipulators, two sizes of actuator modules (the ARM20 and ARM32 actuators) were designed for this demonstration. Each actuator module incorporates a DISCTM amplifier along with a high performance brushless DC motor, position/velocity sensors, gearing, structural bearings, fail-safe brake, and other components to form a pre-engineered package (See Figure 5). Each actuator module utilizes a standardized electro/mechanical interface, which allows a simultaneous connection of electrical power and signal, pneumatic supply and a precise mechanical connection. The specifications for each of the actuators are depicted in Table 1.

By utilizing these actuator modules and interconnecting links and yokes, robotic arms can be assembled in a variety of kinematic (geometric) configurations by selection of appropriate actuators, links and yokes (see Figure 1). Each link module is simply a tubular or linear extension of an actuator module, while yoke adapters convert roll modules into pitch joints (See Figure 6). Pitch actuators can be thought of as the "bending" point in a serial arm. Variations on yoke adapters allow the creation of pitch joints, which are fulloffset, in-line, double-yoke or almost any custom offset. While link modules typically take the form of cylinders extending the length of roll actuators, they may also be built as a "parallel-links" for maximum stiffness between two consecutive pitch modules.

Once a manipulator is constructed, interfacing to the hardware requires a single cable approximately $19 \mathrm{~mm}$ (3/4") diameter, which carries complete power and signals for all joints to the base flange from the system controller. This system controller contains an industrial PC combined with a power supply in a single

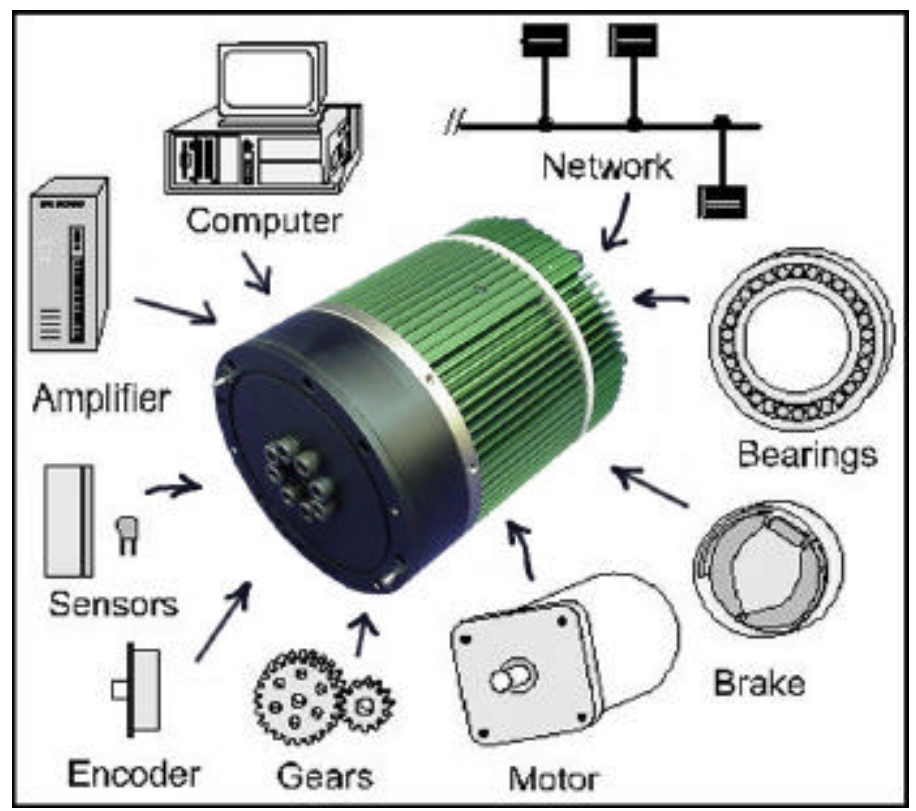

Figure 5. ARM actuator module composition. 


\begin{tabular}{|c|c|c|}
\hline Performance: & ARM20 & ARM32 \\
\hline - Range of Motion & $\pm 270^{\circ}$ & $\pm 270^{\circ}$ \\
\hline - Output Peak Speed & 36 RPM with $80: 1$ Gear train & 23.4 RPM with 100:1 Gear train \\
\hline - Output Peak Torque & $74 \mathrm{~N} \cdot \mathrm{m}$ & $298 \mathrm{~N} \cdot \mathrm{m}$ \\
\hline - Output Continuous Torque & $47 \mathrm{~N} \cdot \mathrm{m}$ & $130 \mathrm{~N} \cdot \mathrm{m}$ \\
\hline - Bearing Load Capacity & $20,000 \mathrm{~N}$ & $10,700 \mathrm{~N}$ \\
\hline - Bearing Overturning Load & $210 \mathrm{~N} \cdot \mathrm{m}$ & $700 \mathrm{~N} \cdot \mathrm{m}$ \\
\hline - Voltage Input Range & $60-320$ Volts & $60-320$ Volts \\
\hline - Rated Current (Cont/Pk) & $1 / 2.5$ Amps & $3.0 / 4.5 \mathrm{Amps}$ \\
\hline \multicolumn{3}{|l|}{ Physical: } \\
\hline - Length & $115 \mathrm{~mm}$ & $159 \mathrm{~mm}$ \\
\hline - Diameter & $97 \mathrm{~mm}$ & $129 \mathrm{~mm}$ \\
\hline - Mass & $2.42 \mathrm{~kg}$ & $6.1 \mathrm{~kg}$ \\
\hline
\end{tabular}
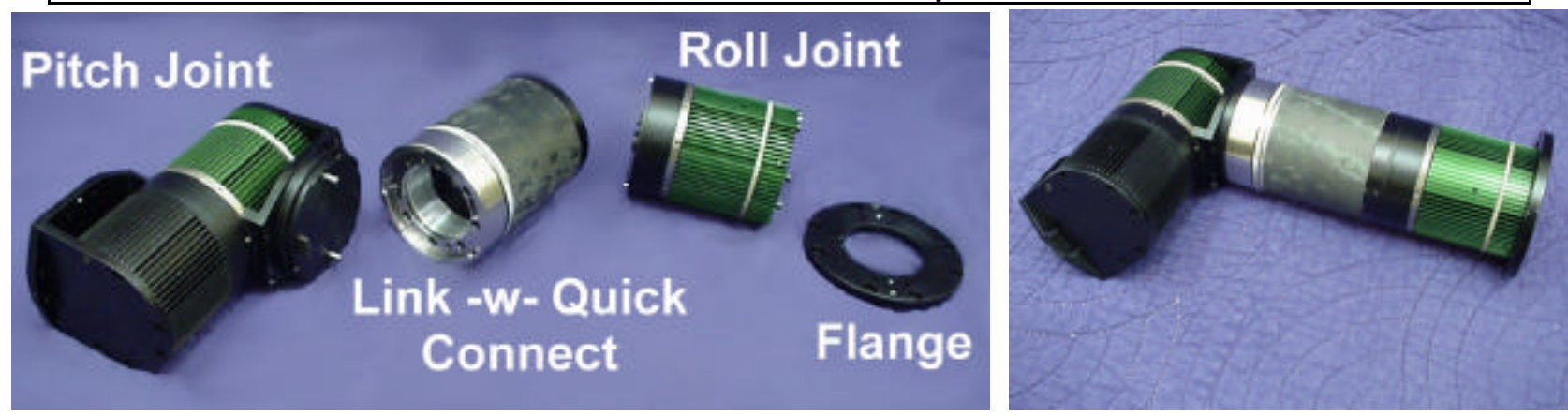

Figure 6: Several ARM20 elements of the modular manipulator system unassembled (Ift) and assembled (rt).

enclosure (typically, 19" x 17" x 7"). The PC is an inherently flexible platform which includes a SERCOS compatible motion control board for coordinating axes and issuing real-time commands onto the network. By using PC based hardware, virtually any open-architecture system control software can be used to run this system. For the systems being designed for this demonstration, Cimetrix system controller software has been selected to provide the ability to program, run simulations and provide a graphical user interface.

In order to allow safe and efficient field serviceability for EM applications, a novel quick-connect mechanism was created so that actuators can easily be joined with or separated from adjacent modules (see Figure 7). Within a single quick-connect interface, electrical, mechanical and pneumatic connections are made simultaneously. These interfaces are capable of generating the high internal forces required for stiff and strong structural connections with only a simple spanner wrench shown in Figure 7. Quick-connections are extremely simple to operate and minimize pinch points that present a hazard to gloves and other worker protective barriers.

The two halves of each quick connect flange are joined by orienting the two flanges such that electrical connectors and dowel pins are aligned, mating the halves together and rotating by hand an interlocking collar through approximately $45^{\circ}$ of rotation. Once the interlocking collar is hand tightened in position, the joint is secure and the operator may release the module being attached to relax. To fully secure the quick connect mechanism to specifications, the operator may apply a simple spanner wrench to the knurled collar and rotate until sufficiently tight.

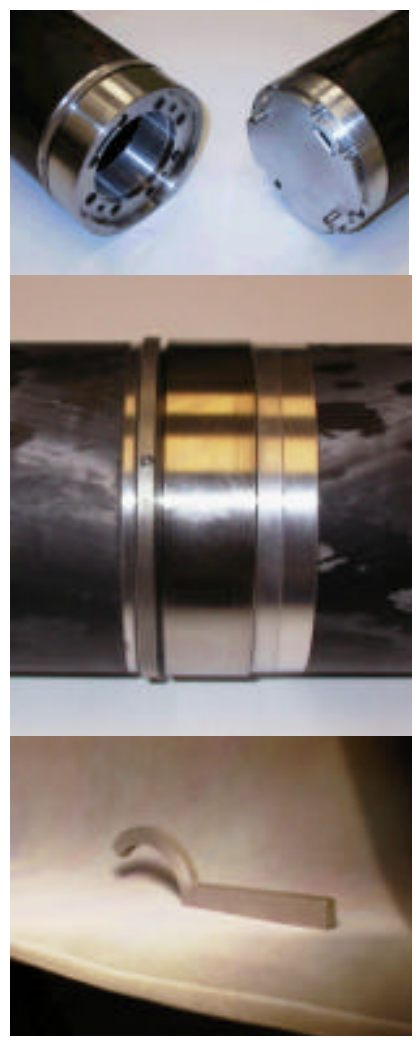

Figure 7: ARM quick connect mechanism (open/closed). 


\begin{tabular}{|l|c|c|c|}
\hline \multicolumn{1}{|c|}{ Item } & LR-Mate 100i & Manipulator \#1 & Manipulator \#2 \\
\hline Degrees of freedom & 5 & 4 & 4 \\
\hline Wrist Payload & $3 \mathrm{~kg}$ & $3 \mathrm{~kg}$ & $9.5 \mathrm{~kg}$ \\
\hline Mass with 1.2 m Track $(26.3 \mathrm{~kg})$ & $32 \mathrm{~kg}$ & $40.9 \mathrm{~kg}$ & $51.9 \mathrm{~kg}$ \\
\hline Mass with Base Roll & $32 \mathrm{~kg}$ & $18.3 \mathrm{~kg}$ & $34.58 \mathrm{~kg}$ \\
\hline Repeatability & $+/-0.04 \mathrm{~mm}$ & $+/-0.08 \mathrm{~mm}$ & $+/-0.08 \mathrm{~mm}$ \\
\hline Reach from base pitch to Wrist Plate & $620 \mathrm{~mm}$ & $640 \mathrm{~mm}$ & $960 \mathrm{~mm}$ \\
\hline
\end{tabular}

Table 2: Baseline and modular manipulator specifications.

\section{System Operation}

Table 2 summarizes the operational parameters of the manipulators shown in Figure 4 and the baseline robot. Both manipulators were controlled using the integrated power supply and system controller. The power supply contains the utility interface, the main power conditioning circuitry, the control $\left(24 V_{D C}\right)$ supply, the system controller power supply, a PSSI board, relay control logic, and the system controller. The supply can be configured to interface to either single phase 120 or three-phase $208 \mathrm{~V}_{\mathrm{AC}}$. Figure 8 depicts the exterior of the supply. Each of these will be expounded on in the paragraphs below.

The front panel of the power supply contains the local interface to the system controller as well as the control circuitry for bringing up the power supply. The four switches on the front panel perform the following functions: Power On/Off switch/breaker, Off/PC On/Energize High Power Bus key selector switch, PC Reset, and Emergency Stop. The switch/breaker initiates the power up of the system. The key selector switch is a 3-position switch with the following logic from left to right: Normally Open (NO) (Off), Normally Closed (NC) (PC On), and Momentary Closed (MC) with spring return to center (Energize Main Bus). When switched from the NO to the NC position, the switch turns on power to the system controller (PC) and the system controller begins its boot sequence. At the appropriate time after the system controller has initialized the amplifiers, the key switch is turned to the MC position to energize the main bus. The emergency stop loop light is illuminated anytime the emergency loop is not closed. The machine enable light is activated when the system controller enables the DISC'M. The Power Bus lamp is lit when there is voltage on the main power bus. The PC On light is activated when the key switch is turned to PC On. There are two fans on the front panel, each capable of moving up to $120 \mathrm{CFM}$ of air.

As shown in Figure 8, the rear panel has an assortment of connectors to interface to the external world. The power supply can be configured to take in either $120 \mathrm{~V}_{\mathrm{AC}}$, single phase or $208 \mathrm{~V}_{\mathrm{AC}}$, three-phase power. The four connectors on the left column are from top to bottom for the external emergency and safety stop loops, external end effector power in, light tower interface, and external signal interface. The emergency and safety stop loop connector allow external loops to be closed remotely from the system controller. If this functionality is not desired, then a loop back plug must be used for the system to function properly. The external light tower interface outputs the same four signals that are represented on the front panel. The external signal interface allows the system controller to interface to local digital and analog $\mathrm{I} / \mathrm{O}$ signals. The two external FSMA fiber optic connectors are for closing the SERCOS loop with an external SERCOS amplifier. For the demonstration, these connectors were used to interface to a Pacific Scientific OC940
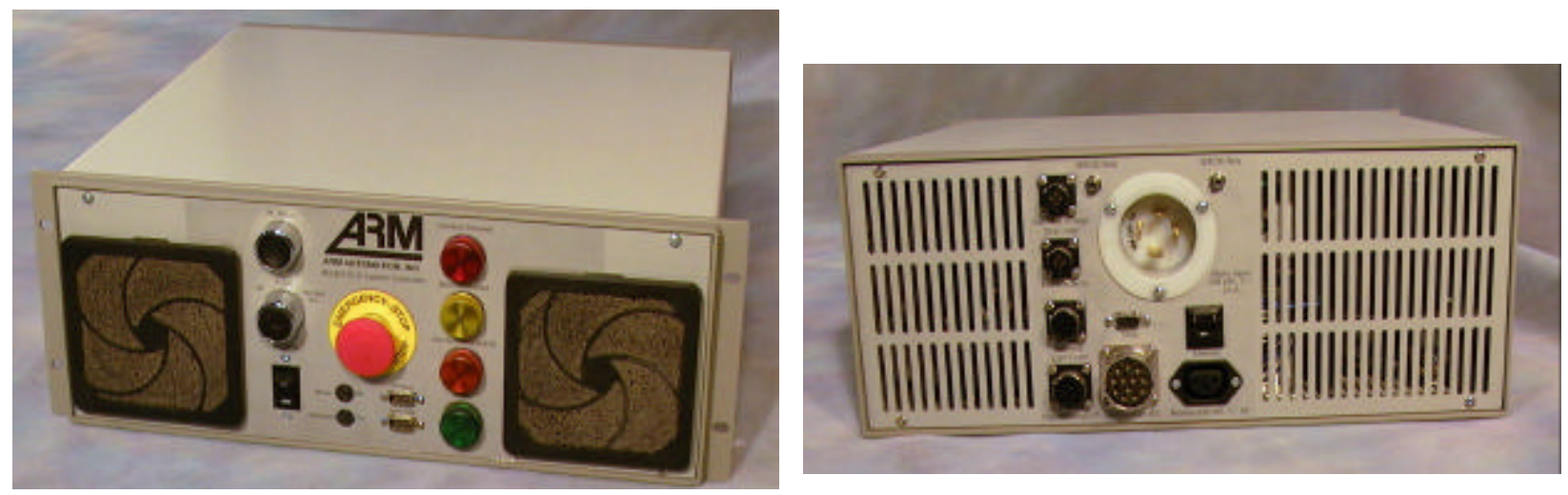

Figure 8: Front and rear panels of power supply. 
SERCOS Amplifier operating on the same ring as the DISCTMS. The Ethernet connector is for placing the system controller on a local network. This is necessary to remotely operate the system controller. The 12pin interface for the umbilical cord is located on the bottom center. The 12 pins carry the end effector power (2), main motor power (2), control power (2), earth ground (1), and data communications (5).

The system controller is a single board computer consisting of an Ethernet controller, an IDE controller, a PC-104 expansion bus, several digital I/O and analog input lines, and a Pentium Class processor with 64M of memory. The system contains a 4 Gigabyte hard drive. An MEI SERCOS motion control card is resident on the PC-104 bus. This card is used to control the trajectories on the individual axes. The system controller's operating system is NT 4.0. The open architecture system controller used for this task is Cimetrix.

The main power supply is designed to function from 60 to $320 \mathrm{VDC}$. It is designed to deliver up to $16 \mathrm{~A}$ of current. It can store over 10 Joules of regenerative energy before it must dump the dynamic braking energy from the motors into power resistors thermally isolated underneath the storage capacitor in the high power section. The PSSI board controls the dumping of this energy. The PSSI board also controls the soft starting of the main power bus for initially charging the large capacitor up to the main bus voltage.

The PSSI board provides the glue logic for the power supply, the relay logic, the system controller, and the communications. The board has the following functionality: System controller interface, general purpose external digital $\mathrm{I} / \mathrm{O}$ and analog inputs, front and real panel indicator lamp control, SERCOS fiber optics signal to RS-485 conversion, internal power supply signal conditioning, relay ladder logic drivers, end effector, control and end effector current sensing, ground fault sensing, main power bus soft starting, overvoltage sensing and dynamic braking, and board power conditioning.

The relay ladder logic is designed with a specific order in which the robot is to be energized per RIA standards presented in [13]. After the breaker is switched on, the first relay is engaged by turning the key switch to the center position. This turns on the power to the system controller, which then initiates its boot sequence. At this point the green PC On light on the front panel is lit. The next rung on the ladder logic is the emergency stop loop (E-Stop). If any one of these contacts is opened, then the E-Stop is open causing all rungs after the E-Stop to also be open. The red light on the system controller front panel is lit when this loop is opened. As soon as the E-Stop loop is closed, the end effector power select relay, the system controller can control the end effector on/off relay and the control power supply relay to the manipulator. The manipulator's safety stop loop can be closed as soon as the control power is available to the manipulator. The safety stop loop is used to remove the motor power from the manipulator. The system controller, an over-current on the main or control power bus, or an external safety stop can break this loop. The main bus is then powered up by turning the key switch clockwise to the momentary position. As soon as the bus is power up to the full voltage, the orange light on the front panel is lit. The machine enable light can then be turned on and off by the system controller software.

The system controller coordinates the motion of the joints of the modular robot. The software control software architecture chosen for this project was an open-architecture system developed by Cimetrix. This controller uses a client-server format with the server running in the power supply and the client running either on the power supply or externally and communicating to the server using a TCP/IP protocol (see Figure 9). The client generates the manipulator's joint set points and passes them to the server. The server then generates the desired motion profile and passes the commands on to a motion card interface. The server monitors external signals through the $\mathrm{I} / \mathrm{O}$ signal interface. The CODE (Cimetrix Open Development Environment) interface is a set of library function calls that creates the interface between the user's application environment and the server. The user develops an application in C, Visual $\mathrm{C}_{++}$, Visual Basic, or Delphi using library CODE function calls supplied by Cimetrix. These function calls then pass information to the server. The server is a multi-threaded program operating on an NT 4.0 platform that performs the motion control, error monitoring, and I/O control. The server then passed motion commands to the motion $\mathrm{I} / \mathrm{O}$ card interface. 


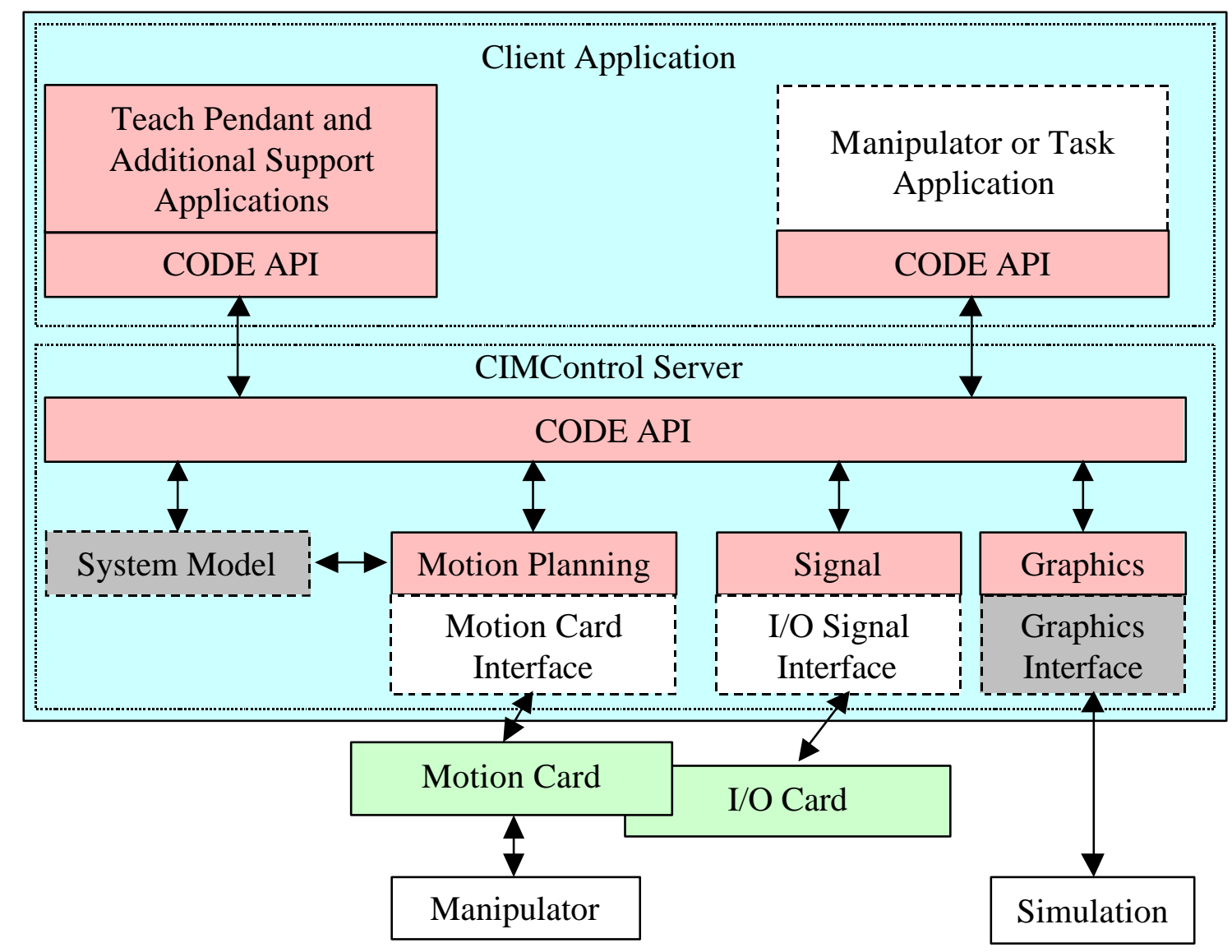

Figure 9: Block diagram of Cimetrix control hierarchy. 


\section{SECTION 3 \\ PERFORMANCE}

\section{Demonstration Plan}

The D\&D Focus Area strives "to develop and demonstrate improved technologies and systems to solve customer-identified needs to characterize, deactivate, survey and maintain, decontaminate, dismantle, and dispose of DOE surplus facilities and their contents, and to facilitate the acceptance, approval, transfer, commercialization and implementation of these technologies and systems" [14]. In an effort to follow this mission, a major objective of this project was to demonstrate the viability of modular robotics technology applied to EM applications, in general, and the D\&D FA, in particular. Thus, this project's goal was to show that modular robotics is an improved automation technology that addresses the needs of the EM FAs.

This project developed two manipulator designs for automating glovebox operations: (1) A flexible, more complex system, which meets the needs of a wide range of glovebox tasks and (2) One less complicated, which meets the specific requirements of the ARIES or PIP automation cells. The beauty of the modular approach shines as the second system is simply constructed by removing modular components from the first, and can be configured within a brief amount of time. Both systems were built and demonstrated at ARM's facility. This strategy tested the ability of the modular approach to accommodate multiple system reconfigurations. The following describes the requirements envisioned for each system. Both systems were to be controlled with the same open-architecture PC-based system controller described in Section 2.

\section{DOE Demonstration And System Quantification}

The system demonstration consisted of two parts: 1) demonstrating the usefulness of the quick connects for passing the modules through the glove port and then assembling the manipulator and 2) demonstrating the assembly of a convenience can inside a stainless steel primary can using the two configurations shown in Figure 4.

\section{Assembly Of Manipulator Using Quick Connects}

Figure 3 in Section 1 depicts the assembly sequence of a modular manipulator using quick connects. A joint, link and half of a quick connect are assembled external to the glovebox and then passed into the glovebox through a glove port. The pieces of the manipulator are then assembled in the glovebox by the following procedure:

- Locate retaining ring in open position.

- $\quad$ Pick up adjoining module assembly and insert in quick connect by aligning dowel pins.

- Turn retaining ring into closed position.

- Used spanner wrench to secure link in place by turning the preload ring.

- Repeat with next joint.

The simplicity of the quick connects allows a manipulator to be assembled/disassembled in a matter of minutes. Since the quick connect is a very accurate interface, a manipulator can be assembled external to the glovebox and then fully qualified before it is disassembled and passed into a confined environment.

\footnotetext{
Assembly Of A Convenience Can Inside A Primary Can

There are several procedures associated with the processing of pure Plutonium into a MOX fuel. Figure 10 demonstrates several of these tasks. A simple demonstration of the capabilities of the modular manipulator developed under this project is the assembly of a convenience can inside a stainless steel primary can. An assembled convenience can is a hermetically sealed canister that contains Plutonium that has been converted to a MOX fuel. The convenience can, when full, weighs approximately $4.8 \mathrm{~kg}$ and the complete assembly weights $5.1 \mathrm{~kg}$. For the demonstration, the clearance for the convenience can inside the primary can is less than $1.2 \mathrm{~mm}$ and the clearance for the lid on the primary can is less than $0.55 \mathrm{~mm}$.
} 

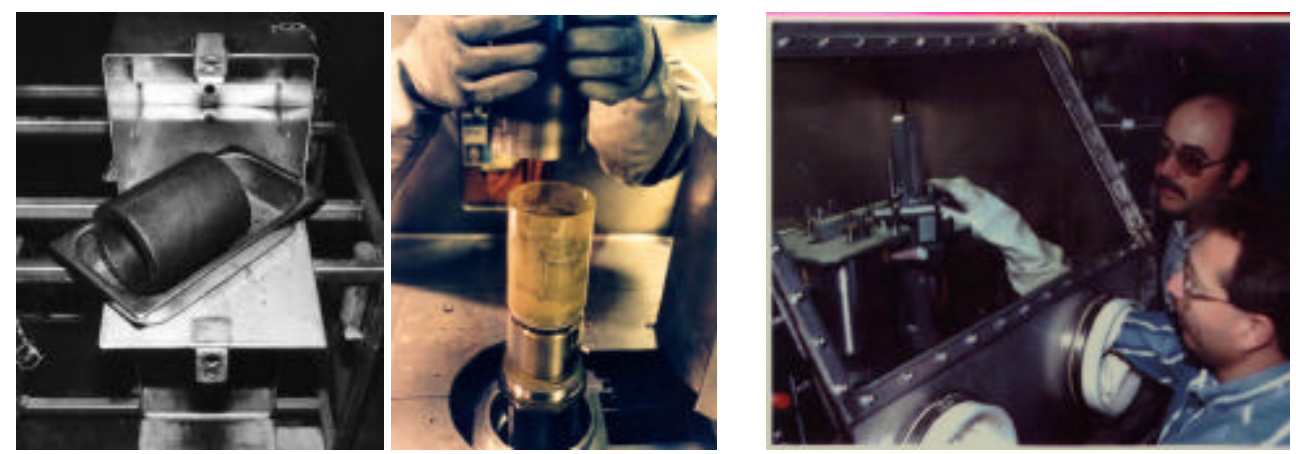

Figure 10: Insertion of MOX (Ift) into convenience can (ctr) and primary can (rt) [15].

Two demonstrations were performed, one with an empty convenience can using a 4 DOF system with the arm consisting of ARM20s and one with a full can weighing $4.8 \mathrm{~kg}$ using a 4 DOF system comprised of ARM32s for the lower two joints and an ARM20 for the distal joint. Figure 11 shows the sequence of the first manipulator assembling the canisters and then moving the complete assembly. Figure 12 shows the sequence of the second manipulator assembling the canisters and then moving the complete assembly. Note that the first two joints in the second manipulator are larger resulting in an increased payload capacity. A jig was manufactured for positioning the convenience container, primary container and lid. This test not only demonstrates the repeatability of the manipulator but also the agility of the kinematics of this configuration.

\section{Results}

The successful demonstration of the modular technology developed under this project is a significant engineering feat. However, at its current state, the technology is not such that one can purchase actuators

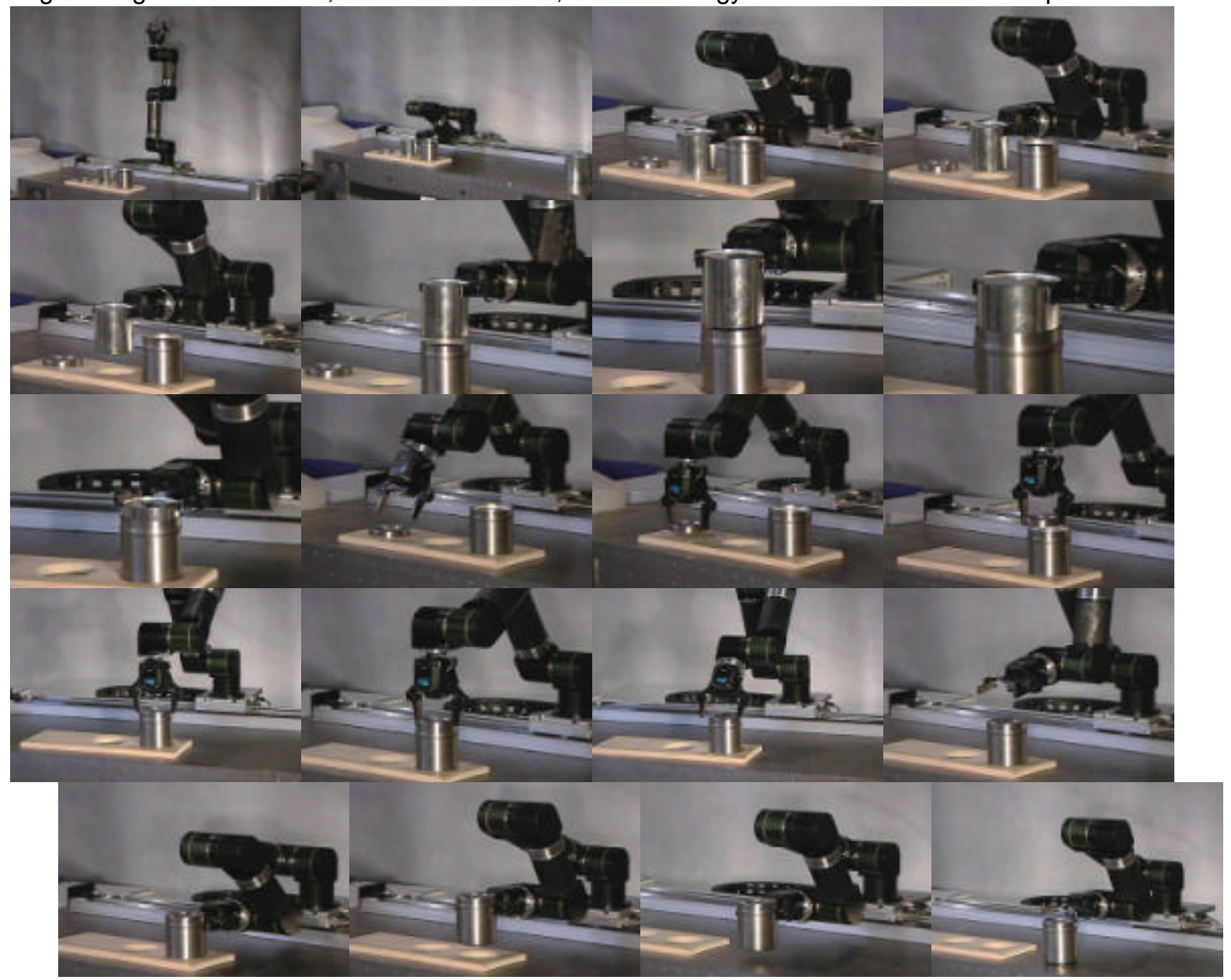

Figure 11: Smaller modular manipulator assembling Plutonium canisters. 


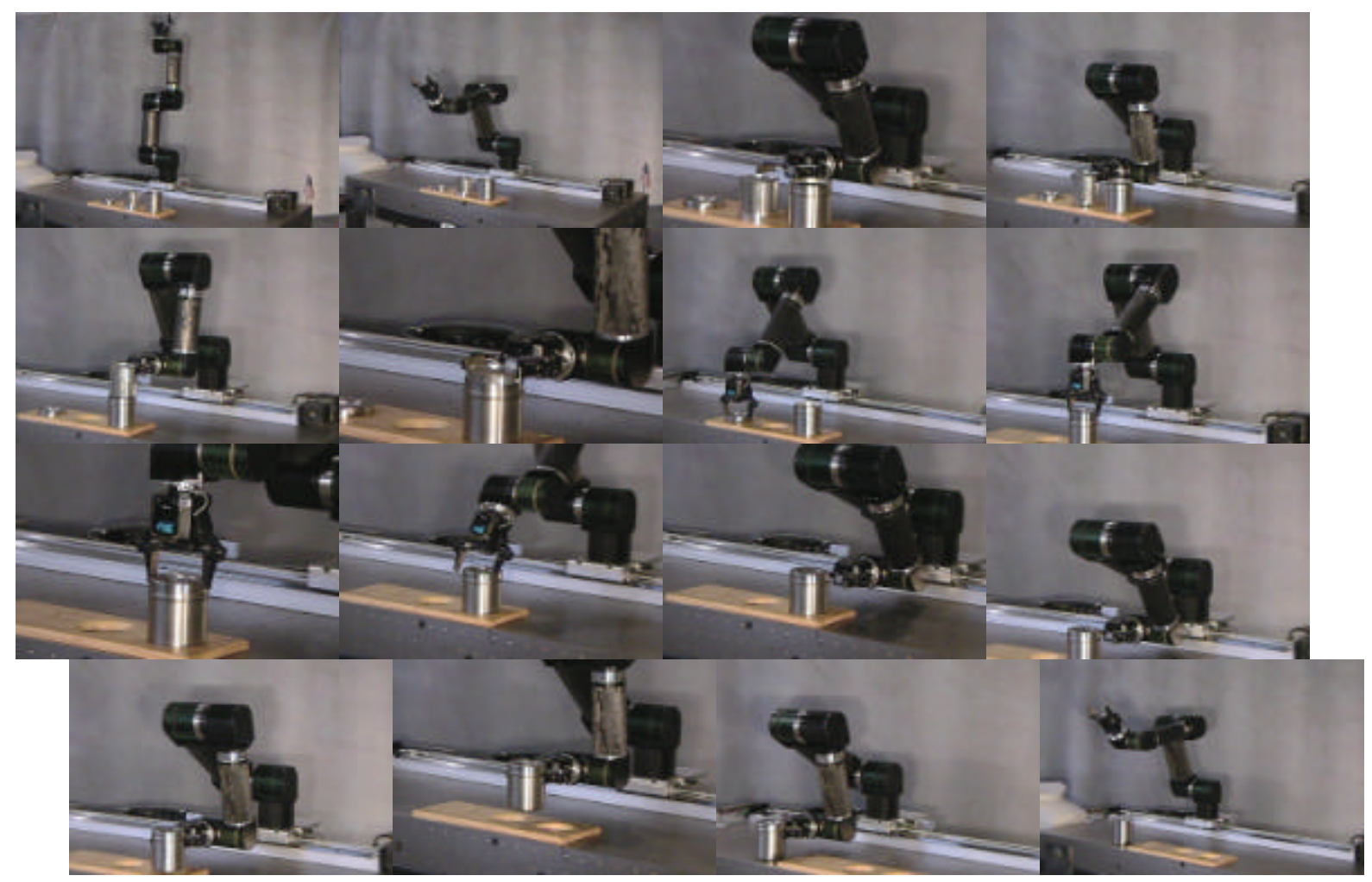

Figure 12: Larger modular manipulator assembling Plutonium canisters.

off-the-shelf and build one's own manipulator. The very fact that a modular system can be tailored to a task means that each system will always have a certain degree of customization. As such, it is difficult to directly compare this technology to the baseline of the LR-Mate 100i. Nonetheless, five technology advancements that were addressed in the original proposal were demonstrated by modular robotics: 1) Increased net payload to weight ratio; 2) Smaller umbilical cords; 3) Capacity for customization; 4) Easily repairable or replaceable components; and 5) Reconfigurable. In addition, it was shown that it is possible to introduce automation through a glove port into existing gloveboxes without compromising personnel safety or automation features.

Observations resulting from the testing indicate that error handling at the system level need to be handled in a methodical manner such that the system does not sporadically shutdown. The manipulator performed exceptionally smooth once the system controller was upgraded to a new version that eliminated program errors associated with an earlier version. Videotape records of the demonstrations were taken and are available upon request. 


\title{
SECTION 4 TECHNOLOGY APPLICABILITY AND ALTERNATIVES
}

\section{Competing Technologies}

\begin{abstract}
Baseline Technology
Los Alamos National Laboratories (LANL) is designing an automated cell for the ARIES line [16]. In this glovebox, LANL is combining two operations: welding and electro-decontamination of the material container. The system utilizes two FANUC LR-Mate 100i robots, one on the 'hot' side and one on the cold side (see Figure 2 in Section 1). The LR-Mate 100i's specifications are shown in Table 2 in Section 2. This robot is traditionally used for part loading operations. While not ideal for the task at hand, it is presently the best commercially available option. The biggest obstacle associated with using this manipulator for glovebox automation is maintenance and repair within the confines of a glovebox. Even a task as simple as removing the cap from the grease zerk fitting becomes nearly impossible with gloves. Consequently, very few failures will be repairable inside the glovebox, and hence, the entire LR-Mate is viewed as a disposable unit. This creates significant challenges in several areas: 1) Removal and replacement of the manipulator, 2) Disposal of the failed manipulator and 3) Calibration of the new manipulator. After significant effort, LANL and SNL have devised a clever system by which a failed LR-Mate may be lowered down through a large portal in the glovebox into a bag and drummed for disposal. This system utilizes a linear guideway system to prevent Plutonium spillage due to the robot tipping over. The resulting operation is elaborate and requires time and care to perform. Despite the novel approach, it still has the additional disadvantage in that it cannot be retrofitted to existing gloveboxes and has yet to be qualified for safety [12]. The LR-Mate's encoders use a battery located in the base to them backup and maintain factory calibration. This battery must be removed during the installation of the manipulator into the glovebox causing the system to loose its factory calibration. Furthermore, the LR-Mate's payload capacity is inadequate to address the needs of APP.
\end{abstract}

\section{Other Competing Technologies}

Other competing technologies for removing personnel from handling hazardous materials include custom robotics. While fully custom systems such as [17] or [18] have been built, they do not leverage the volume production of maintainability that commercial robotics does. As part of the development of this technology, ARM compiled a survey of the best available technologies in a topical report for the DOE [9].

\section{Technology Applicability}

There exist many EM applications that are in need of workable solutions to specific robotic automation problems. Some of these focus areas are addressed in [9]. Examples include dual-arm robotics for decontamination and dismantlement, manipulators for sorting through mixed waste and systems for remote characterization and sampling. Many of these tasks are of human scale and could easily be addressed with manipulators built from the currently available sizes of actuator modules. Other operations such as heavier duty D\&D tasks would require robots built from one or two larger sizes of actuator modules in order to wield large power tools and move heavy pieces of structure. This architecture has been designed to support this expansion.

\section{Patents/Commercialization/Sponsor}

Multiple invention disclosures have been filed for a patent. At the time of the publication of this ITSR, the patents currently have the status of "Patent Pending" and are awaiting approval for filing. 


\section{SECTION 5 \\ COST}

\section{Introduction}

The greatest benefit of automation and robotics comes in terms of worker safety. Any automation that removes humans from the risk of exposure provides a great and almost immeasurable service. As the modular approach offers a viable solution for glovebox automation in new and existing systems that currently have no alternative but to use human labor, it can often be justified on this basis alone. An evaluation must include the total life cycle costs associated with the automation in order to make a fair comparison between the use of personnel and automation. The technological advantages of modular robotics will decrease to an overall life cycle cost of a project by lowering the maintenance costs associated with a custom robot, decreasing timelines for customization of automation, etc. This section will present a comparison of some of the life cycle costs/savings against the baseline of the LR-Mate 100i and custom robotic systems.

\section{Methodology}

This analysis is based on calculating the estimated total life cycle costs for a custom robotic system, an LR Mate $100 \mathrm{i}$, and a modular system. In presenting a life cycle cost comparison for glovebox manipulators, the following issues were taken into account: initial cost, glovebox customization, introduction of manipulator into glovebox, calibration of manipulator inside of glovebox, repair of manipulator inside of glovebox, disposal of broken joints and disposal of complete manipulator. Table 3 presents the estimated life cycle cost for a custom manipulator (designed by the DOE personnel), a LR-Mate 100i and a 4 DOF modular system similar to that shown in Figure 4 (b). At the present time and state of the modular technology, the per unit sales price for a P-R-R-R manipulator comprised of a linear track, two ARM32s and an ARM20 is estimated at roughly $\$ 120,000$ depending upon the exact configuration which takes into account a degree of customization associated with a particular task. Major assumptions in arriving at these estimates are as follows:

- The materials for producing the custom manipulator cost $\$ 75,000$.

- The custom manipulator takes three man-years to design and build.

- The custom manipulator is of similar size to the modular manipulator for estimating cost of disposal.

- Individual LR-Mate joints are not repairable and the complete manipulator is disposable.

- The custom manipulator has similar specifications to the modular manipulator.

- All manipulators a single joint actuator at the same time. This is reasonable for the LR-Mate and modular manipulator since both use optical encoders which are the lowest radiation resistant components in the system. If the custom manipulator has a high radiation tolerance, then its initial cost would be higher than the estimated time and materials. It is also assumed that only one joint fails and needs to be replaced.

- The linear track is not disposed. Only the motor driving the linear track. The volume of the modular manipulator is less than half the LR-Mate. The custom designs volume is similar to that of the custom manipulator.

- The savings for removing DOE personnel is the same for all systems and not included in the overall system comparison.

Additionally, the cost comparison of introducing these manipulators to an existing glovebox cannot be made since the LR-Mate cannot be introduced into an existing glovebox due to the amount of customization required of the glovebox. Furthermore, the payload of the LR-Mate is not sufficient to perform many of the tasks involved with handling of MOX fuel.

\section{Cost Analysis}

\section{Life Cycle Cost Incurred}




\begin{tabular}{|c|c|c|c|}
\hline Description & Custom Robot & LR-Mate 100i & Modular Robot \\
\hline Initial Cost & $\$ 777,000$ & $\$ 50,000$ & $\$ 120,000$ \\
\hline Glovebox Customization & $\$ 9,360$ & $\$ 37,440$ & $\$ 9,360$ \\
\hline Place Manipulator in Glovebox & $\$ 936$ & $\$ 5,616$ & $\$ 936$ \\
\hline Calibrate Manipulator & $\$ 234$ & $\$ 1,872$ & $\$ 234$ \\
\hline Repair Manipulator Joint & $\$ 35,000$ & $\$ 50,000$ & $\$ 15,000$ \\
\hline Remove and Replace Joint & $\$ 1,872$ & $\$ 11,232$ & $\$ 1,872$ \\
\hline Place Manipulator in Glovebox & $\$ 936$ & $\$ 5,616$ & $\$ 936$ \\
\hline Calibrate Manipulator & $\$ 234$ & $\$ 1,872$ & $\$ 234$ \\
\hline Dispose of Broken Joint & $\$ 200$ & $\$ 15,000$ & $\$ 200$ \\
\hline Remove Broken Manipulator & $\$ 936$ & $\$ 5,616$ & $\$ 936$ \\
\hline $\begin{array}{c}\text { Dispose of Broken } \\
\text { Manipulator }\end{array}$ & $\$ 7,500$ & $\$ 15,000$ & $\$ 7,500$ \\
\hline Total Life Cycle Cost & $\underline{\mathbf{\$ 8 3 3 , 2 7 2}}$ & $\underline{\mathbf{\$ 1 9 3 , 6 4 8}}$ & $\underline{\mathbf{\$ 1 5 6 , 2 7 2}}$ \\
\hline
\end{tabular}

Table 3: Cost comparison of glovebox manipulators.

There are many scenarios for implementation of these technologies. This analysis chose a very rudimentary approach. While the total life cycle costs associated with automation are much more complex than those presented herein, it does present a basis for comparing the technologies. The analysis below justifies the numbers presented in Table 3.

Since the LR-Mate 100i is a monolithic device, DOE personnel anticipate that a 'hot' robot may be treated more as a disposable item, rather than a maintainable piece of equipment [12], [19]. This process is estimated to take six man-days for removal, acquisition, installation, and recalibration. A modular manipulator, on the other hand, can be broken down inside the glovebox and the failed joint removed through a simple procedure as shown in the previous section easily taking less than one-man day. Thus, only the broken component will require disposal as compared to a complete manipulator.

According to [20] and [21], the TRansUranic Waste (TRUW) disposal costs to the DOE sites per cubic meter range from $\$ 35,000$ to $\$ 100,000$ with a majority of the costs falling around $\$ 50,000$. The disposal volume of the LR-Mate is approximately $0.15 \mathrm{~m}^{3}$ and the disposal volume of an ARM module is $0.002 \mathrm{~m}^{3}$ thus the disposal cost will be 75 times less than that of the LR-Mate which is estimated to range from $\$ 5,250$ to $\$ 15,000$.

As commented by [19], the ability of modular robots to be customized to a task rather than the task being retrofitted to conform to the robot will save significant time. Additionally, unlike pure custom robotics, commercial repair parts will be readily available to maintain these systems. On the conservative side, it takes at least two to three man-years to develop a custom manipulator. Using the labor rate of $\$ 117 / \mathrm{man}$ hour as presented in [11] and a 2000 hour man-year, this means that a custom designed manipulator will cost the DOE between $\$ 468,000$ and $\$ 702,000$ plus the cost of materials. Additionally, the ability to purchase an off-the-shelf system versus building a custom manipulator, frees up DOE Site personnel to address the automation tasks rather than just the automation.

\section{Cost Reduction}

The nuclear industry estimates that it costs between $\$ 2,000$ [22] and $\$ 10,000$ [23] per rem eliminated worker. The LANL Laboratory Procedure (LP) 107-16 provides the following guidelines for estimated person dosage costs for determining the cost savings for implementing ALARA principles: $\$ 2,000$ per rem-person dose if individual is below $2 / 3$ recommended amount of rem/year and $\$ 10,000$ per person-rem thereafter [24]. For purposes of drawing a cost comparison, this section will assume half the personnel will fall below and the other half will go over the $2 / 3$ recommended amount. This will effectively present a cost of approximately $\$ 6,000$ person-rem. This is a reasonable assumption since the required maximum annual dosage is presently set at 2 rem with anticipation of moving to 1 rem in which case, all workers will reach their $2 / 3$ maximum annual dose.

LANL estimates that the pit disassembly operation will annually expose, on average, an individual worker to an estimated 750 mrem per year. They estimate this operation will require 120 individuals to complete the task resulting in 90 person-rem/year dose rate [25]. Adding the pit disassembly dose rate estimate from SRS of $500 \mathrm{mrem} / \mathrm{year}$, the LANL process will incur an additional $60 \mathrm{mrem}$-person/year in disassembling the pit. The SRS has proposed two approaches for disposing of the weapons grade plutonium: 1) Pit Disassembly and plutonium immobilization, and 2) Pit disassembly with a portion converted to MOX fuel and the remaining portion immobilized. The estimated dosages for the first method are $192 \mathrm{mrem}$-person/year 


\begin{tabular}{|c|c|c|r|}
\hline Plutonium Reduction Method & \# of Personnel & Max. Person-rem/yr & Est. Cost Reduction $^{\mathbf{1}^{*}}$ \\
\hline LANL MOX Conversion & 120 & 150 & $\$ 450,000$ \\
\hline SRS Approach \#1 & 674 & 410 & $\$ 1,230,000$ \\
\hline SRS Approach \#2 & 991 & 561 & $\$ 1,683,000$ \\
\hline
\end{tabular}

${ }^{1}$ Estimated that automation will reduce handling by $50 \%$ thereby reducing exposure by $50 \%$.

Table 4: Estimated cost reduction for the automation implementations.

and $218 \mathrm{mrem}$-person/year for pit disassembly and immobilization, respectively. This yields a total dosage of $410 \mathrm{mrem}$-person/year with an average worker dose of $618 \mathrm{mrem} / \mathrm{year}$. The estimated dosages for the second method are $192 \mathrm{mrem}$-person/year, $194 \mathrm{mrem}$-person/year and $175 \mathrm{mrem}$-person/year for pit disassembly, pit immobilization and MOX conversion, respectively. This yields a total dosage of $561 \mathrm{mrem}-$ person/year with an average worker dose of 565 mrem/year (26]). Table 4 summarizes the estimated cost reduction if half of these personnel were removed from the exposure.

\section{Return On Investment}

Each LANL MOX conversion demonstration line will require two manipulators: one for the pit disassembly and one for the canning and measuring process. LANL is anticipating using only a single line with two manipulators. The SRS approach \#1 calls for 2 lines to perform the pit disassembly and immobilization. It is anticipated each line will incorporate a gantry robot and two robots similar to the LR Mate. Approach \#2 requires two lines to perform the pit disassembly, MOX conversion, and immobilization. It is anticipated that each line will incorporate a gantry robot and two robots similar to the LR Mate. Thus, Approach \#1 will utilize 4 manipulators and Approach \#2 will utilize 6 manipulators. Based on this analysis, all three automation solutions show a positive Return On Investment except for the single line at LANL. Table 5 summarizes the information presented herein. As this analysis shows, the modular technology achieves at least a $\$ 100,000$ in cost savings for almost all types of implementations over the baseline technology and can achieve a total savings in excess of $\$ 700 \mathrm{~K}$ if implemented on a large scale basis with even greater potential when deployed in other DOE applications. Also, note that in applications with existing gloveboxes that cannot use an LR-Mate, the savings are relative to people and will be greater.

\section{Cost Conclusions}

As was demonstrated by this project, modular robotic technology can bring automation to existing gloveboxes reducing worker exposure and thereby reducing DOE's total cost. While it is difficult to estimate

\begin{tabular}{|c|r|r|r|}
\hline Plutonium Reduction Method & Est. Cost & Est. Cost Reduction & Est. Savings/<Loss> \\
\hline \multicolumn{5}{|c|}{ Modular Manipulator } \\
\hline LANL MOX Conversion & $\$ 156,272$ & $\$ 450,000$ & $\$ 137,456$ \\
\hline SRS Approach \#1 & $\$ 625,088$ & $\$ 1,230,000$ & $\$ 604,912$ \\
\hline SRS Approach \#2 & $\$ 937,632$ & $\$ 1,683,000$ & $\$ 745,368$ \\
\hline \multicolumn{5}{|c|}{ Custom Robot } \\
\hline LANL MOX Conversion & $\$ 964,544$ & $\$ 450,000$ & $\$ 2,912$ \\
\hline SRS Approach \#1 & $\$ 1,227,088$ & $\$ 1,230,000$ & $\$ 193,368$ \\
\hline SRS Approach \#2 & $\$ 1,489,632$ & $\$ 1,683,000$ & $\$ 62,704$ \\
\hline \multicolumn{5}{|c|}{ LR-Mate 100i } \\
\hline LANL MOX Conversion & $\$ 193,648$ & $\$ 450,000$ & $\$ 455,408$ \\
\hline SRS Approach \#1 & $\$ 774,592$ & $\$ 1,230,000$ & $\$ 521,112$ \\
\hline SRS Approach \#2 & $\$ 1,161,888$ &
\end{tabular}

Table 5: Estimated Return on Investment for baseline automation implementations. 
the total savings of reducing worker exposure, history has shown that automation within the DOE complex has proven to decrease worker accidents by decreasing their exposure [27]. The lines at LANL and SRS are excellent candidates to demonstrate this technology and prove that it is a viable and cost effective solution to the many DOE automation needs. 


\section{SECTION 6 \\ REGULATORY AND POLICY ISSUES}

\section{Regulatory Considerations}

Before the modules can become a commercial product that can be purchased off-the-shelf, they will need to undergo more system level testing in real applications. Along that line, ARM is pursuing opportunities to advance the technology by getting systems into UT-RRG, LANL, and SNL for further testing. If funding is found to purchase a system by these groups, then outside testing by these knowledgeable personnel can be used to increase the overall reliability of these systems. This testing will be necessary to get the modular robotic technology approved by the Defense Nuclear Facilities Safety Board for glovebox use. Certification by the DNFSB will be crucial in the integration of modular robotics into glovebox operations.

Secondary waste streams generated by modular robotics include failed modules. While these modules, when operated in a 'hot' box, will need decontaminated and disposed, they will generate significantly less volume than the baseline technology.

\section{Safety, Risks, Benefits, and Community Reaction}

Modular robotics technology reduces the risks associated with high exposure to radiation while following good ALARA and industrial automation practices. As with any piece of automation, though, hazards exist that must be mitigated. The primary danger exists during equipment maintenance when workers through gloves may come into contact with contaminated material stuck to a robot in a "hot" glovebox environment. At present, the control system hierarchy is designed to meet RIA Industrial Standards. In addition to this, code and possibly light curtains will need to be put in place to insure that the manipulator does not come in contact with the glovebox walls. Other potential hazards from the electrical energy $\left(300 V_{D C}\right)$ associated with the manipulator power supply are reduced by using standard industrial practices.

The professional community reaction is positive as this technology provides them with a necessary tool to complete tasks prescribed by DOE's Ten Year Plan. 


\section{SECTION 7 \\ LESSONS LEARNED}

\section{Implementation Considerations}

Industry and the DOE are increasingly interested in the potential advantages of modular robotics technology, as a viable solution to problems that present automation technology does not solve. Such DOE applications included material processing in existing gloveboxes, characterization problems needing custom kinematics, and mixed waste sorting requiring low DOF. In order to realize these advantages, this technology must be qualified and used by the Site personnel. The current commercial status of the modular robotics technology at the conclusion of the demonstration is that it is ready for beta type testing. It is at the stage where an experienced engineer in the field of robotics can fully utilize the technology. The technology that still needs the most effort before the technology can be commercialized is the system level software. Originally, ARM had anticipated that the software purchased off-the-shelf would be sufficient in controlling the manipulator. However, the interface between the system level software, which was designed for analog amplifiers, and the SERCOS communication system took more effort than anticipated. As a result, ARM has not significantly developed the error handling capability of the system level software. Another area of investigation is the level of radiation hardness for the system. ARM has done some preliminary investigation into the radiation hardness of some of the components but has not done a complete study of the system.

\section{Technology Limitations And Needs For Future Development}

\section{Component Development}

There are several areas of the project that will need further study: the error handling process of the system controller, the noise immunity of the communications signal, the corrections to the PSI and CCI boards, the brake material life, the implementation of a position loop in the DISC ${ }^{\mathrm{TM}}$ and the winding connections of the ARM32.

The system controller presently handles all errors by completely shutting down the system and removing power from the DISCTM . This removal of power results in the loss of information regarding the cause of the error if it exists in an amplifier on the SERCOS ring. The system controller is designed to work with analog amplifiers and is not designed to handle the information that can completely characterized the system that is sent back from a digital amplifier. An error handling parser needs to be written to determine the overall severity of the error and then determine if the system can recover from the error and continue to operate.

The ARM20 can easily operate the main power bus at an excess of $340 V_{D C}$ without any effects of noise but the ARM32 currently functions up to $200 V_{D C}$ before noise effects start to show up on the communications signals. The system is currently using an RS-485 line driver/receiver. ARM is considering changing this transmission technology to Low Voltage Differential Signaling (LVDS) in an effort to overcome some of the shortcomings of the RS-485 communications medium.

Both the PSI and $\mathrm{CCl}$ boards had some very minor problems that need to be addressed. These problems are presently corrected using jumper wires soldered externally on the board.

To meet density goals while incorporating a brake into the actuator design, ARM needed to pursue a custom parking brake design. The material selected for use as the frictional surface against the brake disk had a high initial coefficient of friction. ARM found that this coefficient degraded over time due to heat and wear. Additionally, there is no way to adjust the pressure applied by the brake after assembly to account for tolerances in the coefficient of friction. Both of these issues will need to be addressed in future redesigns.

A position loop with trajectory generation would be beneficial to the design of the system controller since the motion control board could then be eliminated. The DISC ${ }^{\mathrm{TM}} \mathrm{S}$ currently only have velocity and current control loops implemented. However, the DISC ${ }^{\mathrm{TM}}$ S do have the SERCOS functional structure in place such that the position loop can easily be implemented in future revisions. 
The manufacturer of motor windings for the ARM32 terminated the connections at a high stress point where they are tied together and brought off of the motor. System vibration over time has resulted in failure of three of the original five ARM32's windings. This can be fixed by tying off the windings to more flexible wire under the coil bands and then bring off the flexible wire rather than the magnetic wire that is currently brought out. This will be implemented on the next redesign.

\section{Radiation Hardening}

The radiation levels in many of the DOE applications range from a few $\mathrm{mRad} / \mathrm{hr}$ for filter change-out applications to up to approximately $8,000 \mathrm{Rad} / \mathrm{hr}$ in canyon remediation applications. For the most part, components for the modular actuators were selected such that a radiation-hardened component could be substituted at a higher cost. A discussion below will cover some of the issues regarding radiation hardness of the components inside the modules. This discussion will be broken down into three sections: Mechanical Component Selection, wire selection, and electronics. Only the Total lonizing Dose (TID) levels will be discussed. The data for the discussion presented below came from [23], [28], [29], [30], and [31].

The mechanical components that are most effected by ionizing radiation are the seals, motor and solenoid windings, and grease and separators in the bearings and gear train. The seals used in the initial design are not radiation resistant although similar seals can be acquired that are radiation resistant to at least 100 MRad (Si). These seals cost an order of magnitude greater than the commercially available seals used in the actuator. The polyethylene insulation on the motor and solenoid windings is good to at least $100 \mathrm{MRad}$ (Si) [32]. The grease used in the gear train is a commercial variant of an equivalent grease used by both the Aerospace and Space industries. The radiation tolerant grease is good to about $10 \mathrm{MRad}$ (Si) [32] but it has a higher cost and is toxic. The bearings retaining rings and grease lubricants can be selected to increase their radiation tolerance but were not to keep development costs down. The current devices with the nylon retainers are estimated to be good to approximately 1 MRad (Si) [32].

The wire insulation selected for the wire coil in the actuator was comprised of silicone rubber which is radiation tolerant to more than $10 \mathrm{MRad}(\mathrm{Si})$ [32]. This insulation also exhibited good lubrication qualities for the wire coil that was in torsion but they were very susceptible to nicks in the insulation which would lead to shorts to ground. The wire leads coming off the motor and sensors were coated in Teflon insulation and are good to about $30 \mathrm{KRad}$ (Si) [28].

The electronics can be subdivided into two categories: Sensors and Controller. Since the sensors and the DISC $^{\text {TM }}$ are enclosed inside an aluminum shell, Alpha and Beta radiation sources will have no effect on the degradation of their electronics. Consequently, only gamma radiation particles will have any effect on the life of the electronics. The sensors consist of Hall-Effect devices, thermistors, an RTD sensor, an optical encoder, a reflective optical sensor, and a switch. The switch is estimated to have a capacity to withstand at least $1 \mathrm{MRad}(\mathrm{Si})$. The Hall-Effect devices are CMOS based technology which technology is tolerant between the range of 3 to $50 \mathrm{KRad}$ (Si) [31], although according to [23], they tend to range closer to 20 $\mathrm{KRad}(\mathrm{Si})$. The thermistors and RTD sensor can withstand more than $1 \mathrm{MRad}$ (Si). According to properties of similar data taken from [30], the encoder head should be tolerant to at least $3 \mathrm{KRad}(\mathrm{Si})$ and components tested were tolerant to over $100 \mathrm{KRad}(\mathrm{Si})$.

The passives on the DISC ${ }^{\mathrm{TM}}$ consist of ceramic capacitors, metal film and carbon film resistors and silicon varistors of which all can withstand more than 1e8 Rad (Si) [23]. The optocouplers on the board have a tolerance between 3 and $100 \mathrm{KRad}(\mathrm{Si})$. No data was found for the crystal oscillator but it is assumed to be at least as tolerant as the CMOS devices and [23] has shown them to be at least $100 \mathrm{KRad}$ (Si). The microcontroller and digital logic on the CCI and PSI boards are CMOS based technology which technology is tolerant between the range of 3 to $50 \mathrm{KRad}(\mathrm{Si})$ [31], although according to [28], they tend to range closer to $25 \mathrm{KRad}(\mathrm{Si})$. The DC-DC is not presently radiation-hardened but radiation-hardened versions with a guaranteed TID of $50 \mathrm{KRad}(\mathrm{Si})$ or $100 \mathrm{KRad}(\mathrm{Si})$ can be purchased. The transistors can be radiationhardened to $1 \mathrm{MRad}$ (Si) [29]. The transistor drivers are comprised of proprietary HVIC technology. No data is available on this technology, but it is comprised of Al-Si using large gates. It is therefore estimated to be at least tolerant to $10 \mathrm{KRad}(\mathrm{Si})$.

From the data presented herein, it is estimated that the DISC ${ }^{\mathrm{TM}}$ s are tolerant to at least $3 \mathrm{KRad}(\mathrm{Si})$ although conclusive results can only be obtained through actual testing. ARM is presently talking with Dr. Tulenko of The University of Florida about performing future radiation tests on the DISC ${ }^{\mathrm{TM}}$ electronics. This is the only conclusive method to arrive at any conclusive evidence as to actual level of radiation-tolerance the DISC ${ }^{\mathrm{TM}} \mathrm{S}$. 


\section{Technology Selection Considerations}

The successful demonstration of the modular technology was a significant engineering feat. However, in its current state, the technology and support tools are not refined to the level that anyone can configure a custom manipulator from off-the-shelf modules. The very fact that a modular system can be tailored to a task means that each system will always have a certain degree of customization. As such, it is difficult to directly compare this technology to the baseline of the LR-Mate 100i. Nonetheless, five technology advancements were addressed by this technology: 1 ) Increased net payload to weight ratio (from 3:32 to 1:2.7); 2) Smaller umbilical cords (two 50 wire cables to a single 12 wire cable); 3) Capacity for customization; 4) Easily repairable or replaceable components; and 5) Reconfigurable. At present, this technology needs to get in the hands of knowledgeable engineers such that it can be fully qualified for glovebox operations. The demonstration proved that the technology is a viable alternative to DOE's current practices but additional refinement and testing will need to take place before this is realized. As such, ARM is presently offering this technology to any early adopters and is willing to design a system to meet the customer's needs.

In an effort to further the technology, the implementation of this modular approach to robotic automation within DOE-EM tasks is now underway for one specific task, automated characterization and mapping of contamination. Under a SBIR grant (\#DE FG03-00ER 82950.000), this modular system is being used to create a series of robotic positioning devices for delivering and locating the sensor head assembly of the 3-D ICAS characterization system. This characterization system provides comprehensive, real-time contaminant analysis and mapping in a portable package. Through the use of ARM's modular robotic system, a series of custom light-payload, long-reach manipulators will be constructed to locate this sensor system much more effectively, making possible in-situ, real-time analysis of site contamination and location. At present, ARM is working with candidate facilities to locate a specific deployment opportunity for this combined system and expects to begin testing in 2002. 


\section{APPENDIX A REFERENCES}

[1] U.S. Department of Energy (DOE) D\&D Focus Area, 2000. "Deactivation and Decommissioning Focus Area QUARTERLY REPORT - April - June 2000 Activities," Deactivation and Decommissioning Focus Area, July.

[2] U.S. Department of Energy (DOE), ESA-EPE Group Office, 2000. "The MOVER System," EPE News, Vol. 1, No. 1, pg. 1. September.

[3] U.S. Department of Energy (DOE) Robotics and Intelligent Machines, 1998. "Robotics And Intelligent Machines In The U.S. Department Of Energy: A Critical Technology Roadmap," Sandia Report, SAND98-2401. October.

[4] Bronson, M., Ebbinghaus, B., Armantrout, G. and Gray. L., 1997 "Dealing with a Dangerous Surplus from the Cold War," Science and Technology Review (pp. 5-13). Los Alamos, NM: Department of Energy.

[5] U.S. Department of Energy (DOE) Office of Defense Programs, 1996. "Safety Evaluation Report of the Los Alamos National Laboratory Technical Area 55 Plutonium Facility 4 Safety Analysis Report and Technical Safety Requirements," December.

[6] U.S. Department of Energy (DOE) Nuclear Materials Focus Area, 1999. "Nuclear Materials Focus Area FY 2000 - FY 2004 Multi-Year Program Plan," DOE/ID-10728, November.

[7] U.S. Department of Energy (DOE), 1998. "Accelerating Cleanup: Path to Closure," DOE/EM-0362, June.

[8] Geisinger, J. W., 1999. "Survey of Application Requirements for Robotics within DOE-EM Focus Areas," Conference Proceedings from American Nuclear Society - 8th Topical Meeting on Robotics \& Remote System, Pittsburgh, PA, April 25-29"th.

[9] Black, D. and Grupinski, S., "Evaluation of State-of-the-Art Manipulators and Requirements for DOE Robotics Applications," Topical Report, October 1998.

[10] Lyman, E. S., 1998. "DOE reprocessing Policy and The Irreversibility of Plutonium Disposition", Department of Energy Nuclear Control Institute, April.

[11] Dyches, G., B. Fiscus, L. Hamilton, G. Hovis, R. Jones, E. Kriikku, B. Randall, M. Restivo, J. Steed, and C. Ward, 1999. "Plutonium Immobilization Can Loading FY99 Component Test Report," WSRC-TR-1999-00318.

[12] McKee, R., 1998. Conversations with Randy McKee during site visit to Sandia National Labs, June 18.

[13] Robotic Industries Association/American National Standards Institute, Inc., 1999. "American National Standard for Industrial Robots and Robot Systems - Safety Requirements."

[14] U.S. Department of Energy (DOE) \&D Focus Area, 2000. "D\&D Focus Area Mission Statement," http://www.fetc.doe.gov/dd/, September.

[15] U.S. Department of Energy (DOE) Material Deposition Focus Area, 2001. "Pu Photo Gallery - Pit Disassembly and Conversion", "http://www.esa.lanl.gov/groups/esaepe/aries.html.

[16] U.S. Department of Energy (DOE) NMFA, 2000. "Advanced Recovery and Integrated Extraction System (ARIES)," http://www.lanl.gov/orgs/esa/epe/ar_proj2000_aries.html.

[17] Dennison, D., R. L. Hurd, R. D. Merrill, and T. C. Reitz, 1995. "Application of Glovebox Robotics to Hazardous Waste Management," ANS 6th Topical Meeting on Robotics and Remote Systems Conference Proceedings, Monterey, California, February 5-10.

[18] U.S. Department of Energy (DOE), 1998. "Rocky Flats Pu Stabilization System Behind Schedule, Over Budget," Weapons Complex Monitor, May 25, pp.5-6.

[19] Turner, C., 2001. Email from Cameron Turner regarding glovebox automation at LANL, July $9^{\text {th }}$.

[20] Schaade, J., 1998. "FY98 Accomplishments - Nuclear Materials Stabilization," Presentation.

[21] U.S. Department of Energy (DOE), 2000. "DOE/AL Site Technology Coordinating Group FY-2000 Problem Statements: Los Alamos National Laboratory."

[22] U.S. Department of Energy (DOE). "Houdini TM -II Remotely Operated Vehicle System" DOE Document Number OST/TMS ID 2085, Industry Programs and Robotics Crosscutting Program. December 1999.

[23] Bennett, P.C. and L. D. Posey. "RHOBOT: Radiation Hardened Robotics," SANDIA REPORT, SAND97-2405. October 1997.

[24] U.S. Department of Energy (DOE) Los Alamos National Laboratory, 1998. "ALARA Program Protects Workers and the Public," The Actinide Research: Nuclear Materials Research and Technology Quarterly", 1st Quarter. 
[25] U.S. Department of Energy (DOE) Office of Fissile Materials Disposition, 1998. "Pit Disassembly and Conversion Demonstration Environmental Assessment and Research and Development Activities," Washington, DC, August.

[26] U.S. Department of Energy (DOE) Office of the Federal Register, 1997. "Surplus Plutonium Disposition Environmental Impact Statement," Notice of Intent, 62 FR 28009, Federal Register, Washington, DC, May 22.

[27] U.S. Department of Energy (DOE) Savannah River Site, 2001. "Tritium Facility Operation," http://www.srs.gov/general/srtech/tritweb/operations.htm.

[28] Bostock, J. L. and F. R. Sias, 1994. "Radiation Hardening for Terrestrial Robots For An Intelligent Inspection and Survey Robot," Report Prepared for the DOE under Contract No. DE-AC2192MC29115. April.

[29] International Rectifier (IR), 1998. "International Rectifier's Total Dose Radiation Hardness Assurance (RHA) Test Program." Application Note No. 999.

[30] Hewlett Packard (HP), 1984. "Radiation Immunity of Hewlett-Packard Optocouplers," Application Note No. 1023.

[31] National Aeronautical Space Agency (NASA), 1996. "Space Radiation Effects On Electric Components In Low-Earth Orbit." Preferred Reliability Practices: Practice No. PD-ED-1258, April.

[32] Harper, C. A., 1997. "Electronic Packaging and Interconnection Handbook." 2nd Edition. McGrawHill. 


\section{APPENDIX B ACRONYMS AND ABBREVIATIONS}

\begin{tabular}{|c|c|}
\hline DOE & Department of Energy \\
\hline TID & Total lonizing Dose \\
\hline FA & Focus Area \\
\hline EM & Environmental Management \\
\hline DISC ${ }^{\mathrm{TM}}$ & Distributed Intelligent Servo Control \\
\hline ARM & ARM Automation, Inc. \\
\hline ALARA & As Low As Reasonably Achievable \\
\hline LANL & Los Alamos National Laboratory \\
\hline ANL & Argonne National Laboratory \\
\hline HAN & Hanford Site \\
\hline SNL & Sandia National Laboratory \\
\hline SRS & Savannah River Site \\
\hline RFETS & Rocky Flats Environmental Technology Site \\
\hline D\&D & Deactivation \& Decommissioning \\
\hline MD & Materials Disposition \\
\hline DP & Defense Programs \\
\hline MW & Mixed Waste \\
\hline $\mathrm{CCl}$ & Control and Communications Interface \\
\hline kg & Kilogram \\
\hline PIP & Plutonium Immobilization Project \\
\hline ARIES & Advanced Recovery and Integrated Extraction System \\
\hline PSI & Power and Sensor Interface \\
\hline SERCOS & SErial Real-time COmmunications System \\
\hline MOX & Metal Oxide \\
\hline PC & Personal Computer \\
\hline RPM & Revolutions Per Minute \\
\hline $\mathrm{N}$ & Newton \\
\hline UT-RRG & The University of Texas at Austin Robotics Research Group \\
\hline DC & Direct Current \\
\hline AC & Alternating Current \\
\hline NO & Normally Open \\
\hline NC & Normally Closed \\
\hline MC & Momentary Closed \\
\hline CFM & Cubic Feet per Minute \\
\hline FSMA & Fiber Sub Miniature Assembly \\
\hline SVGA & Super Video Graphics Array \\
\hline CE & Conformité Européenne \\
\hline MEI & Motion Engineering, Inc. \\
\hline LVDS & Low Voltage Differential Signaling \\
\hline CODE & Cimetrix Open Development Environment \\
\hline IDE & Integrated Drive Electronics \\
\hline W & Watt \\
\hline PSSI & Power Supply and System Interface \\
\hline I/O & Input/Output \\
\hline E-Stop & Emergency Stop \\
\hline TCP/IP & Transmission Control Protocol/Internet Protocol \\
\hline TRUW & TRansUranic Waste \\
\hline $\mathrm{R}$ & Roll \\
\hline $\mathrm{P}$ & Pitch \\
\hline LP & Laboratory Procedure \\
\hline DOF & Degree Of Freedom \\
\hline
\end{tabular}

